\title{
FIBROSITIS AND PAIN
}

\section{BY J. B. HARMAN}

THE object of this paper is to draw attention to a type of pain which is not yet generally recognised as sometimes arising from fibrositis, and which is usually attributed to disease of viscera if it occurs in the trunk, or to brachialgia or sciatica from other causes if it occurs in the shoulder or buttock. The present time is opportune, partly on account of the revival of interest in treatment by anæsthesia, which provides a convenient method of checking the diagnosis, and partly because recent work has demonstrated the circumstances in which this type of pain may be felt.

The symptoms usually associated with fibrositis vary from a vague stiffness to an agonising burning or stabbing pain, and in all cases the pain is made worse by movement of the affected part and by cold and damp, etc. It has a "sharp" quality such as is found with painful lesions of the superficial structures of the body, however produced, and, like them, is easily localised. On the other hand, the type which we wish particularly to consider has a "dull " quality, ranging from a mere ache to an intolerable bursting or cramp, such as may arise from the viscera; and, more important still, the pain is so poorly localised that its greatest intensity may be felt at some distance from its point of origin.

Cases have recently been described ${ }^{1}$ in which a dull pain was felt in the front of the abdomen or chest, which was nevertheless due to fibrositis of the back. These cases were all referred with a diagnosis of some visceral disease on account of the site of the pain and the tenderness, muscular rigidity and skin hyperæsthesia which were present. In no case was there any demonstrable disease of the organs under suspicion, and a detailed history showed that, although the site and quality of the pain were consistent with the original diagnosis, yet its exacerbation and relief were dependent on position and movement of the trunk, indicating a somatic origin; while its course and frequent association with other rheumatic conditions suggested that fibrositis was the 
cause. This diagnosis proved to be correct, because it was possible to relieve the symptoms by injecting procaine into tender spots which could be discovered deep in the musculature of the back.

Pains referred from the back are well recognised mimics of abdominal disease, and, in the absence of any definite lesion such as tuberculosis or malignant deposits in the spine, are usually attributed to osteo-arthritis of the spine, or to neuritis in the sense of an inflammation of the nerve trunk. The cure by injections of procaine showed that the pain was not due to any of these causes, for the needle was not placed anywhere near the nerve trunks or the joints, nor indeed was osteo-arthritis present in the majority.

Since it can be demonstrated that fibrositis may cause either a sharp well-localised pain, or a dull poorly-localised one, it is pertinent to enquire what determines the difference. Kellgren ${ }^{2}$ has studied the pain sensation resulting from the injection of small amounts of hypertonic saline into various somatic structures. He found that injections into the skin, fascia and subcutaneous periosteum gave the well-localised pricking or burning sensation with which everyone is familiar from superficial injuries. If, howevero the injection was made into the deep muscles or ligaments, the paiff. had a dull quality such as is felt from a sprained ankle or dyspepsia, or in angina pectoris, and was not accurately localised to its source, but felt diffusely throughout the corresponding spinal segment. The maximum pain sensation was in many cases some distance from the lesion, tending towards the periphery of the segment, so that the pain might be felt in the front of the body or distally in the limbs even when the injection was in the interspinous ligaments. The pain was accompanied by hyperresthesia of the skin and muscles and by spasm in the area of its distribution. So far as is known, these two types of pain perception, the superficial and the deep, do not depend on the nature of the lesion, but are determined entirely by the depth of the structure that is injured. It may be, therefore, that a study of the quality of any pain can only indicate the approximate depth of the lesion from the surface, while the diagnosis of the nature of $\mathrm{N}$ the lesion must depend on the periodicity of the pain, its clinical course and associated symptoms. These modes of pain perception are not, however, two separate categories, but two extremes of a continuous series, for a lesion may be situated in a mid-posi- 
tion, or extend in depth from the surface, giving rise to mixed symptoms.

The sort of symptoms which would result from fibrositis of any part of the back may now be discussed. The more superficial forms with local pain anywhere between the sacrum and the occiput need not detain us. The symptoms of deep fibrositis of the trunk with thoracic or abdominal pain have already been referred to, and the headache from nuchal fibrositis and the radiation of lumbago into the side of the buttock or front of the thighs are too well recognised to need further discussion.

The difficulties arise in considering deep lesions around the shoulder or buttock, for these may give rise to syndromes of brachialgia or sciatica. Fibrositis in these situations would on a priori grounds give a pain of segmental distribution in the limb, varying in intensity from a poorly-localised ache to an agonising soreness. There would be tenderness of the muscles in the area of reference and hyperæsthesia of the skin, which by analogy with the abdominal cases mentioned would pass over to analgesia with time. There would be a position of the limb in which pain would be minimal and deviation from this would increase it by stretching hyperæsthetic structures. Direct irritation of the fibrositis in the shoulder or buttock by pressure or movement would result in exacerbation of the pain both locally and throughout the affected area. It would be found that some persons were prone to these and other recognised rheumatic conditions, the individual attacks being precipitated by damp, infections and muscular strain.

So far this reconstruction would apply equally well to brachialgia or sciatica, whatever might be their supposed cause, except that the hypotonia, wasting and weakness of the muscles and diminution of the reflexes in the chronic cases have not been accounted for. Experimental pains can give no information here because they last only a matter of minutes, and are incapable of inducing the signs of chronic disease; nor can a study of referred pains in the trunk provide an analogy, because changes in muscles and reflexes would not be manifest in the abdomen or thorax owing to the anatomy of the part.

In considering further the claim of fibrositis to produce brachialgia and sciatica, it will be helpful to compare it with the evidence on which other suggested causes are based, and to examine the validity of their special diagnostic criteria. It is 
a commonplace of medicine that even such distinct conditions as spinal tumours and malignant or other deposits in the pelvis may in their early stages give symptoms identical with "idiopathic" sciatica. This being the case, it is unlikely that the vaguer entities such as inflammation of the nerve trunks or their roots, strain of the sacro-iliac joint, fibrositis of the shoulder and buttock and so on, will be distinguished clinically with ease. The notable sensory changes, wasting of the muscles and diminution of the tendon reflexes, have been held to indicate that in some way the nerves themselves must be affected. But it has already been shown that this does not hold good for the sensory changes, and muscles may waste, and to a lesser extent reflexes disappear, in chronic inflammations such as rheumatoid arthritis where there is no question of a primary neuropathy; while it has long been known that the muscle wasting of sciatica does not follow the distribution of the peripheral nerves, but that of the segmental supply. Further, if these signs do indeed indicate direct nerve involvement, then strained sacro-iliac joints, as well as fibrositis, must be excluded from the list of possible causes of sciatica.

Various specific signs have from time to time been described as being diagnostic of a particular lesion. Thus the pain resulting from straight leg raising has been held to show that the nerve is diseased because its inflamed fibres may be stretched in this way; but other structures are disturbed besides the nerve, and the pain might equally well be due to stretching of hyperæsthetic muscles and fasciæ, or fibrositis anywhere in the buttock, or to direct movement of a diseased joint. This argument applies to similar diagnostic procedures, for it is difficult to move any part of the body without causing pain, as a patient with severe sciatica will testify. Tenderness of the nerve trunk itself is often described, with the implication that it is the seat of the primary inflammation, but here again it is difficult to be certain that only the nerve is being stimulated when other structures are sensitive, and equally tender places far from the nerve can often be demonstrated, especially if they are sought for with the same confidence and care. Moreover, even if it be admitted that the trunk is tender, it has still to be shown that this means an inflammation there, and not merely a hyperæsthesia predominantly of the nerve trunk rather than of the muscles or fasciæ.

This leads to the conclusion that the distinction by clinical 
examination between the various putative causes of sciatica or brachialgia is very difficult, for those procedures which have been held to be diagnostic of one apply equally well to another, and any difference of opinion is largely a difference of interpretation. The causal lesion of any given case can therefore only be decided by more direct examination. This can be done unequivocally, though by no means simply, for ruptured intervertebral discs, and it is a matter for future experience to show how frequently these occur. The fact that the sciatic trunk is sometimes inflamed has been demonstrated by operation, and it may be assumed that procedures directed to remedying this, such as epidural injection or distension of the sheath with saline or oxygen, do, when successful, confirm the diagnosis. Per contra, their notable failures suggest the opposite. The pathology of strained sacro-iliac joint is purely hypothetical, depending on an analysis of various movements which bring on the pain, and while indeed it may occur and cause sciatica, there is no direct means of examination to prove this to be the origin of a pain which yields to treatment by manipulation or support.

Neither is the claim for fibrositis supported by any direct examination, nor from the nature of the disease is it likely to be. It rests mainly on the experience that brachialgia and sciatica can sometimes be cured by injecting tender spots with procaine, which is a known means of curing fibrositis, and it is difficult to explain on any other hypothesis. The results are clearer with brachialgia, for the shoulder girdle is a simpler structure, and though they are not so convincing in the case of sciatica, an estimate of the frequency of fibrositis based on this test will probably be too low, because procaine injections are by no means a panacea even for obvious superficial fibrositis, and it is difficult to be certain that the correct spot has been injected in so large a structure as the buttock.

Nevertheless it would be rash, on such slender evidence alone, to claim that fibrositis is a general cause of these syndromes, especially in a condition where so many different conclusions have been deduced from the same facts, and it is for this reason that the attempt has been made to show that the suggestion is based on other grounds than the mere results of injection, and to indicate its relationship to other causes and to the perception of deep pain in general. From the point of view of pathology the distinction between the various causes of brachialgia and 
sciatica (ruptured intervertebral disc excluded) is more apparent than real, for whatever structure may be responsible it is agreed that it is the fibrous tissue that is affected, whether this fibrous tissue happens to be in a nerve sheath, a joint capsule, a ligament or a fascial plane.

There is, however, considerable practical importance in knowing where the affected tissue lies, if any more specific therapeutic measures are to be employed than rest, heat, and analgesics, for is the site will decide the choice between procaine injection, epidural injection, distension of the nerve sheath, mobilisation, or support. Since it frequently happens that the responsible lesions cannot be diagnosed clinically with any accuracy, it would be very helpful if some estimate could be made of their relative frequency, for $\stackrel{N}{\sim}$ the appropriate methods could then be used according to the $\vec{\circ}$ probability of any given lesion being present, rather than haphazard, or according to the fashion of the moment.

The conclusion to be emphasised is that although the main symptom of fibrositis is pain, either of the superficial or deep type, with its associated changes in muscle tone and reflexes, yet no analysis of its quality will establish a diagnosis, for these phenomena are not diagnostic of particular lesions, but of modes of pain perception which are dependent on the site of the lesion. This conception of the unity of pain response will correct the tendency to attribute signs and symptoms to one particular lesion which are in reality common to many, and also, by emphasising the many possible causes of pain, will prevent attention from being focussed too exclusively on the most obvious organ of any given segment, whether it be the heart, the appendix or the sciatic nerve. The diagnosis of fibrositis, as of any other lesion, can only be fished out of this common pool by an analysis of the variations of the pain-of its periodicity, of what makes it better or worse, and all those factors which together constitute the natural history of the disease, coupled in favourable cases by the discovery and cure of the local focus of irritation.

\section{SUMMARY}

The type of pain arising from fibrositis of deep structures is not yet generally recognised. The symptoms of deep fibrositis of the trunk are described and compared with similar experimental pains. The claim of fibrositis to produce the syndromes of 
brachialgia and sciatica is discussed and compared with the evidence in support of other causes. The claim is supported by the results of procaine injection in some cases. The syndrome of pain from deep fibrositis is similar to that due to any lesion in a like situation. The diagnosis of fibrositis must therefore rest on the natural history of the disease and the response to treatment.

\section{REFERENCES}

1. Harman, J. B., and Young, R. H. (1940): Lancet, i. 1111.

2. Kellaren, J. H. (1939) : Clin. Sci., iv. 35. 